\title{
Pathogenicity of two novel human-origin H7N9 highly pathogenic avian influenza viruses in chickens and ducks
}

\author{
Taichiro Tanikawa ${ }^{1} \cdot$ Yuko Uchida $^{1} \cdot$ Nobuhiro Takemae $^{1} \cdot$ Ryota Tsunekuni $^{1} \cdot$ Junki Mine ${ }^{1} \cdot$ Ming-Tsan Liu $^{2}$. \\ Ji-Rong Yang ${ }^{2} \cdot$ Masayuki Shirakura $^{3} \cdot$ Shinji Watanabe ${ }^{3} \cdot$ Takato Odagiri $^{3} \cdot$ Takehiko Saito $^{1,4}$
}

Received: 11 July 2018 / Accepted: 27 October 2018 / Published online: 11 December 2018

(c) Springer-Verlag GmbH Austria, part of Springer Nature 2018

\begin{abstract}
Human infection by low-pathogenic avian influenza viruses of the H7N9 subtype was first reported in March 2013 in China. Subsequently, these viruses caused five outbreaks through September 2017. In the fifth outbreak, H7N9 virus possessing a multiple basic amino acid insertion in the cleavage site of hemagglutinin emerged and caused $4 \%$ of all human infections in that period. To date, H7N9 highly pathogenic avian influenza viruses (HPAIVs) have been isolated from poultry, mostly chickens, as well as the environment. To evaluate the relative infectivity of these viruses in poultry, chickens and ducks were subjected to experimental infection with two H7N9 HPAIVs isolated from humans, namely A/Guangdong/17SF003/2016 and A/Taiwan/1/2017. When chickens were inoculated with the HPAIVs at a dose of $10^{6} 50 \%$ egg infectious dose $\left(\operatorname{EID}_{50}\right)$, all chickens died within 2-5 days after inoculation, and the viruses replicated in most of the internal organs examined. The $50 \%$ lethal doses of A/Guangdong/17SF003/2016 and A/Taiwan/1/2017 in chickens were calculated as $10^{3.3}$ and $10^{4.7} \mathrm{EID}_{50}$, respectively. Conversely, none of the ducks inoculated with either virus displayed any clinical signs, and less-efficient virus replication and less shedding were observed in ducks compared to chickens. These findings indicate that chickens, but not ducks, are highly permissive hosts for emerging H7N9 HPAIVs.
\end{abstract}

Handling Editor: Sheela Ramamoorthy.

Taichiro Tanikawa and Yuko Uchida contributed equally to this study.

Takehiko Saito

taksaito@affrc.go.jp

1 Division of Transboundary Animal Disease, National Institute of Animal Health, National Agriculture and Food Research Organization (NARO), 3-1-5 Kannondai, Tsukuba, Ibaraki 305-0856, Japan

2 Center for Research, Diagnostics and Vaccine Development, Centers for Disease Control, Ministry of Health and Welfare, Taipei, Taiwan

3 Influenza Virus Research Center, National Institute of Infectious Diseases, 4-7-1 Gakuen, Musashimurayama, Tokyo 208-0011, Japan

4 United Graduate School of Veterinary Sciences, Gifu University, 1-1 Yanagido, Gifu 501-1193, Japan

\section{Introduction}

The first case of human infection by influenza subtype H7N9, a novel low-pathogenic avian influenza virus (LPAIV), was reported in March 2013 in Shanghai and Anhui, China. The virus caused five epidemics through September 2017. Subsequently, three laboratory-confirmed cases, including one death, were reported by the World Health Organization (WHO) [1]. The fifth epidemic, which started on October 1, 2016, was the largest, comprising 766 laboratory-confirmed cases, including 248 lethal cases [2]. As of May 28, 2018, a total of 1567 laboratory-confirmed cases have been reported, including 615 deaths [1]. The human cases included one patient from Malaysia and two patients from Canada, all of whom had recently visited China [3, 4].

The first H7N9 epidemic occurred mainly in the Yangtze River Delta (YRD) region, which includes Zhejiang, Jiangsu, and Anhui provinces and Shanghai municipality (111/135 cases: $82 \%)$. In the second epidemic, the secondhighest number of cases after the YRD region (144/320: $45 \%$ ) was recorded in the Pearl River Delta (PRD) region (118/320 cases: $37 \%$ ), which includes Guangdong province and the Hong Kong and Macao special administrative 
regions. Before the fourth epidemic, most human cases of H7N9 infection were primarily reported in these regions ( 623 out of 798 cases, $78 \%$ ). However, in the fifth epidemic, the infection was widely distributed in other regions of China (378 out of 766 cases; $49 \%$ ). In addition, during this outbreak, infection by emerging highly pathogenic avian influenza viruses (HPAIVs) of the H7N9 subtype that had acquired a multiple basic amino acid insertion in the cleavage site of hemagglutinin (HA) was observed, specifically 32 cases in Guangxi, Guangdong, Hunan, Shaanxi, Hebei, Henan, Fujian, and Yunnan provinces, as well as in Chinese Taipei $[5,6]$. Through phylogenetic analysis using the HA gene, the emerging H7N9 viruses were mainly divided into two main lineages: the YRD lineage and the PRD lineage [7]. The HPAIVs were found to have originated from H7N9 LPAIVs belonging to the YRD lineage [8]. In this same period, H7N9 HPAIVs belonging to the same lineage were also isolated from chickens and environmental samples in live-bird markets (LBMs) and farms [9-12].

$\mathrm{A} /$ Anhui/1/2013, the H7N9 virus isolated in the first human case, causes fatal infection in mice and asymptomatic infection in chickens [13-16]. Recently emerging HPAIVs of the H7N9 subtype cause high mortality and exhibit efficient propagation in chickens; contrarily, they differentially replicate in the internal organs of Pekin ducks, which exhibit variable virus shedding rates of $0 \%-60 \%$ without causing symptoms, depending on the strain $[11,17]$. In the poultry outbreak caused by H7N9 HPAIVs, approximately 128,000 birds died and 942,000 birds were destroyed as of September 16, 2018 [9]. According to FAO statistics on September 5, 2018, 41 of 43 locations where HPAIVs of the H7N9 subtype were isolated were LBMs and farms [18]. Of the 49 viruses isolated from the birds and the environment, most avian isolates were obtained from chickens, and only two isolates were obtained from ducks [18]. In this study, experimental infection of chickens and ducks using H7N9 HPAIVs isolated from humans was performed, and the preferential infectivity of the H7N9 HPAIVs among poultry was evaluated.

\section{Materials and methods}

\section{Viruses}

A/Anhui/1/2013 (Anhui2013) [19] and A/ Guangdong/17SF003/2016 (Guangdong2016) [20] were provided by the Chinese Center for Disease Control and Prevention (CCDC) through the National Institute of Infectious Diseases (NIH) in Japan. A/Taiwan/1/2017 (Taiwan2017) was isolated at the Centers for Disease Control in Chinese Taipei as described previously [21]. The original Guangdong2016 and Taiwan2017 strains were passaged twice and once, respectively, at the respective institutes. Subsequently, they were passaged once at NIH and once at the National Institute of Animal Health, NARO, Japan, in embryonated eggs. Guangdong2016 and Taiwan2017 were subjected to genetic analysis of viral RNA and animal experiments. Anhui2013 was passaged four times in embryonated eggs as described previously [16].

\section{Genetic analysis}

Viral RNA was extracted from the allantoic fluid of embryonated eggs by using an RNeasy Mini Kit (QIAGEN). The cDNA library was synthesized using a NEBNext Ultra RNA Library Prep Kit (NEB). Viral genome sequencing was performed using a Miseq sequencer and a Miseq Reagent Kit v2 (Illumina). The consensus sequences were generated using FLUGAS software (version 0.9.0, World Fusion, Tokyo, Japan). The DNA sequences of Guangdong2016 and Taiwan2017 were deposited in Global Initiative on Sharing Avian Influenza Data (GISAID; http://platform.gisaid.org/) (Isolate ID: EPI_ISL_280902, EPI_ISL_280894). For comparison of the deduced amino acid sequences, 24 HPAIVs of H7N9 subtype isolated from chickens, which were full-length sequenced, A/Chicken/Huizhou/HZ-3/2016 (EPI_ISL_248796), A/Chicken/Guangzhou/HD621/2017 (EPI_ISL_248816), A/Chicken/Huizhou/HZX/2017 (EPI_ISL_248886), A/Chicken/Zhongshan/ZS/2017 (EPI_ISL_249113), A/Chicken/Huizhou/HZ04/2016 (EPI_ ISL_249114), A/chicken/Guangdong/01.08 SZBJ0011O/2017 (EPI_ISL_259758), A/chicken/Shandong/05.05 DZ056/2017 (EPI_ISL_276783), A/Dressed_chicken/ Guangdong/GZ631/2017 (EPI_ISL_273950), A/chicken/ Heinan/ZZ01/2017 (EPI_ISL_274206), A/chicken/ Fujian/06.06 NP0001/2017 (EPI_ISL_276785), A/chicken/ Guangdong/J1/2017 (EPI_ISL_280466), A/chicken/Guangdong/J2/2017 (EPI_ISL_280467), A/chicken/Guangdong/ SD008/2017 (EPI_ISL_283486), A/chicken/Guangdong/ SD010/2017 (EPI_ISL_283487), A/chicken/Guangdong/ SD027/2017 (EPI_ISL_283495), A/chicken/Guangdong/ SD028/2017 (EPI_ISL_283496), A/chicken/Guangdong/ SD031/2017 (EPI_ISL_283498), A/chicken/Guangdong/ SD032/2017 (EPI_ISL_283499), A/chicken/Guangdong/ SD034/2017 (EPI_ISL_283500), A/chicken/Guangdong/30/2017 (accession no.: MF184011-MF184018), A/ chicken/Guangdong/GD20/2017 (KY751060-KY751290), A/chicken/Guangdong/Q26/2017 (MF280182- MF280203), A/chicken/Guangdong/Q39/2017 (MF280183-MF280204), and A/chicken/Heilongjiang/BQC01/2017 (MG298777MG298784) from the GISAID and the National Center for Biotechnology Information (NCBI; https://www.ncbi.nlm. nih.gov/) (accessed 16 September 2018) were used in this study. 


\section{Animal experiments}

Four-week-old specific-pathogen-free white leghorn chickens and 4-week-old Cherry Valley strain domestic ducks were purchased from Nissei Bio Co., Ltd. (Tokyo, Japan) and Hamada Co. Ltd (Saitama, Japan), respectively. All animal experiments were conducted in biosafety level 3 facilities at the National Institute of Animal Health, Japan, and approved by the committee for the institute's ethics of animal experiments. For survival analysis, each group of four chickens was inoculated intranasally with virus doses of $10^{2}, 10^{4}$, and $10^{6} 50 \%$ egg infectious dose $\left(\operatorname{EID}_{50}\right) / 100$ $\mu \mathrm{L}$, and four ducks were inoculated with a dose of $10^{6}$ $\mathrm{EID}_{50} / 100 \mu \mathrm{L}$. The chickens and ducks were observed for 14 days postinoculation (dpi), and tracheal and cloacal swabs were collected on $1,2,3,5,7,10$, and 14 dpi or at the time of death for virus titration. Swabs were dipped in MEM containing $0.5 \%$ BSA, $25 \mu \mathrm{g}$ of Fungizone per $\mathrm{mL}, 1000$ units of penicillin per $\mathrm{mL}, 1000 \mu \mathrm{g}$ of streptomycin per $\mathrm{mL}, 0.01 \mathrm{M}$ HEPES, and $8.8 \mathrm{mg}$ of $\mathrm{NaHCO}_{3}$ per $\mathrm{mL}$ and then removed from the medium. The medium was then stored at $-80^{\circ} \mathrm{C}$ until titration. To assess viral dissemination in chicken and duck bodies, nine chickens and nine ducks were inoculated with a virus dose of $10^{6}$ $\mathrm{EID}_{50} / 100 \mu \mathrm{L}$. Three chickens each were euthanized at 2,3 , and $4 \mathrm{dpi}$, and three ducks each were euthanized at 2, 4, and 6 dpi. Tracheal, cloacal, and conjunctival swab specimens were taken before euthanasia, and 12 tissues and organs (blood, pancreas, spleen, muscle, liver, trachea, lungs, kidneys, heart, brain, duodenum, and rectum) were excised. Homogenates of the organs were prepared in MEM containing $0.5 \%$ BSA, $25 \mu \mathrm{g}$ of Fungizone per $\mathrm{mL}$, 1000 units of penicillin per $\mathrm{mL}, 1000 \mu \mathrm{g}$ of streptomycin per mL, $0.01 \mathrm{M}$ HEPES, and $8.8 \mathrm{mg}$ of $\mathrm{NaHCO}_{3}$ per $\mathrm{mL}$ as described previously [16] and stored at $-80^{\circ} \mathrm{C}$ until titration. The viral titers in the swab specimens and organ homogenates were calculated as EID $_{50}$ using the Reed and Muench method [22]. Blood samples in surviving chickens or ducks were taken at the end of the observation period for antibody detection. Antibodies against influenza type A virus were detected via ELISA and the HA inhibition (HI) test.

\section{Antibody detection}

To detect antibodies against influenza type A viruses, ELISA was performed using an influenza $A$ virus antibody test kit (IDEXX Laboratories, Inc.). Antibodies against the HA proteins of the viruses were detected using an $\mathrm{HI}$ test according to the WHO Manual on Animal Influenza Diagnosis and Surveillance [23]. The detection limit of the HI test was defined as a titer of $<4$, as the lowest serum dilution was 1:4.

\section{Statistical analysis}

Survival analysis was performed using the Kaplan-Meier method, and survival differences were analyzed using the log-rank test. The differences of viral titers in the swab specimens between Guangdong2016 and Taiwan2017 were analyzed by the Mann-Whitney U-test.

\section{Results}

\section{Pathogenicity of H7N9 HPAIVs in chickens}

The lethality and replication of the human-derived H7N9 HPAIVs in chickens were examined via intranasal inoculation with Guangdong2016 or Taiwan2017. As shown in Fig. 1, all chickens inoculated with $10^{6} \mathrm{EID}_{50}$ of Guangdong2016 and Taiwan 2017 died by 5 dpi, whereas $75 \%$ and $25 \%$, respectively, of chickens inoculated with $10^{4} \mathrm{EID}_{50}$ of these two viruses died by 14 dpi. None of the chickens inoculated with $10^{2} \mathrm{EID}_{50}$ of either virus died or exhibited clinical symptoms. Chickens inoculated with Taiwan 2017 displayed reduced activity 1-3 days before death, and depression and cyanosis of the comb and/or legs were observed on the day of or 1-2 days before death. Facial edema was also observed 1-2 days before death in all four chickens that were infected with a dose of $10^{6}$ EID $_{50}$. Chickens infected with Guangdong2016 exhibited similar clinical symptoms as those infected with Taiwan2017, but one chicken each in the $10^{4}$ and $10^{6} \mathrm{EID}_{50}$ dose groups displayed no clinical symptoms one day before death. Based on the survival rates, the $50 \%$ chicken lethal doses $\left(\mathrm{CLD}_{50}\right)$ of Guangdong2016 and Taiwan2017 were calculated as $10^{3.3}$ and $10^{4.7}$ EID $_{50}$, respectively. At a dose of $10^{6} \mathrm{EID}_{50}$, the mean durations between

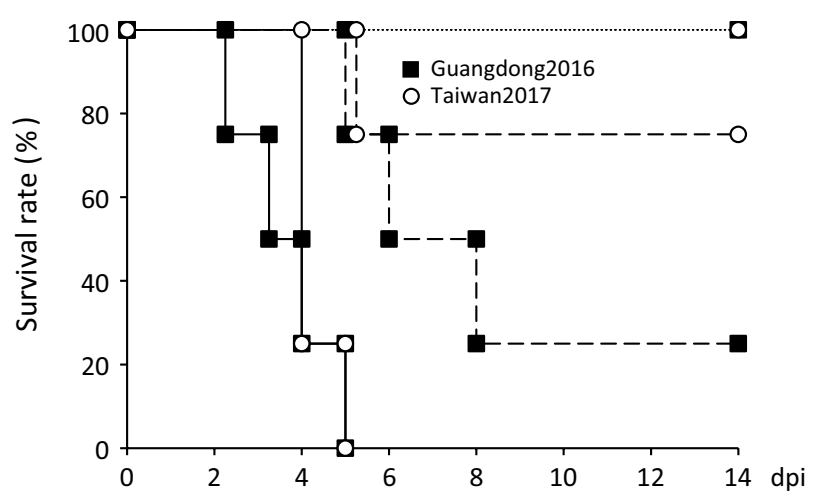

Fig. 1 Survival rates of chickens inoculated intranasally with $10^{2}$ (dotted line), $10^{4}$ (dashed line), or $10^{6}$ (solid line) 50\% egg infective dose of highly pathogenic avian influenza viruses of the H7N9 subtype (four chickens per group). The Guangdong2016 and Taiwan2017 viruses are represented by closed squares and open circles, respectively. dpi, days postinoculation 
inoculation and death in the Guangdong2016 and Taiwan 2017 groups were 3.6 and 4.3 days, respectively, which was not a statistically significant difference. At 1 dpi, shedding of Guangdong2016 was detected in cloacal swabs from three of four chickens $\left(1.60 \pm 0.57 \log _{10} \mathrm{EID}_{50} / \mathrm{mL}\right)$, whereas that of Taiwan2017 was not observed. Regarding viral shedding, the mean highest titer prior to death in the cloaca of chickens infected with $10^{6}$ EID $_{50}$ of Guangdong2016 $\left(4.51 \pm 0.55 \log _{10} \mathrm{EID}_{50} / \mathrm{mL}\right)$ was significantly higher than that for the same dose of Taiwan2017 $\left(3.40 \pm 0.42 \log _{10}\right.$ $\mathrm{EID}_{50} / \mathrm{mL}$ ) (Table 1). At the time of death, there was no significant difference in the average viral titers between the Guangdong2016 and Taiwan2017 groups. Among the chickens that survived for $14 \mathrm{dpi}$ after inoculation with a virus dose of $10^{2}$ or $10^{4} \mathrm{EID}_{50}$, two of five inoculated with Guangdong2016 and three of seven inoculated with Taiwan2017 shed small amounts of virus $\left(0.32 \log _{10} \mathrm{EID}_{50} / \mathrm{mL}\right)$ at 1 or $2 \mathrm{dpi}$. However, according to ELISA, these animals did not exhibit seroconversion (Table 1). The 50\% chicken infectious doses of Guangdong2016 and Taiwan2017 were calculated as $10^{2.7}$ and $10^{3.0} \operatorname{EID}_{50}$, respectively. As shown in Table 2, when chickens were infected with $10^{6} \mathrm{EID}_{50}$ of Guangdong2016 or Taiwan2017, the viruses were detected at average titers of 2.47-5.61 and 2.32-6.38 $\log _{10}$ EID $_{50} / \mathrm{g}$ tissue or $\mathrm{mL}$, respectively, using tissue and swab specimens at 2, 3, and $4 \mathrm{dpi}$, excluding one chicken inoculated with Taiwan2017. The data indicated that human-derived H7N9 HPAIVs are highly pathogenic to chickens.

\section{Pathogenicity of H7N9 HPAIVs in ducks}

Intranasal inoculation with $10^{6} \mathrm{EID}_{50}$ of the viruses was also performed in domestic ducks. In this experiment, Anhui2013, an ancestral strain of the HPAIVs, was also included to evaluate viral pathogenicity in ducks. As shown in Table 3, all ducks survived for 14 days after challenge with any of the strains without any clinical symptoms. Two of four ducks inoculated with Guangdong2016 shed the virus. One duck shed the virus from 1 to $5 \mathrm{dpi}$ in the trachea and at $2 \mathrm{dpi}$ in the cloaca, whereas the second duck shed the virus in the cloaca at $2 \mathrm{dpi}$. The highest titer of 4.02 $\log _{10} \mathrm{EID}_{50} / \mathrm{mL}$ was observed in the trachea in the first duck at $3 \mathrm{dpi}$. Seroconversion was detected in the first duck via ELISA, but not by the HI test with homologous antigen. The latter duck had not seroconverted according to either assay; however, two other ducks that did not shed virus had seroconverted according to the ELISA readout. Only one duck that was inoculated with Taiwan2017 shed the virus at 3 and $5 \mathrm{dpi}$ in the trachea and at $3 \mathrm{dpi}$ in the cloaca, and this animal had seroconverted. No other animal inoculated with this virus exhibited seroconversion. The highest titer in the trachea of $3.02 \log _{10} \mathrm{EID}_{50} / \mathrm{mL}$ was observed at 3 dpi. Among the ducks inoculated with Anhui2013, only one duck shed virus in the cloaca at $7 \mathrm{dpi}$, and none of the ducks seroconverted. As shown in Table 2, no virus was detected in any tissues, excluding the cloacal swab of a duck inoculated with Taiwan 2017 that was euthanized at 6 dpi. These results clearly indicated that human-derived H7N9 viruses were non-lethal for ducks, and their replication was extremely low compared with that in chickens.

\section{Comparison of amino acid sequences between the H7N9 HPAIVs}

To evaluate differences in the amino acid sequences of the viral proteins of the two human isolates and chicken isolates of H7N9 HPAIV and to identify amino acid changes in viral proteins that occurred through egg passage from the original strains [20,21], the deduced amino acid sequences of the two human isolates were compared with a consensus sequence derived from 24 chicken H7N9 HPAIV isolates obtained from the GISAID and the NCBI database. As shown in Table 4, over half of the consensus amino acid residues (27/43) were conserved in Guangdong2016, whereas only 15 residues were conserved in Taiwan2017. Taiwan 2017 has a potential glycosylation site at positions $128-130$ in HA1, unlike Guangdong2016 and the chicken isolates. In addition, the C-terminal region of NS1 of Guangdong2016 and the chicken isolates was truncated by 20 amino acids compared with that of Taiwan2017. After several viral passages in eggs, six amino acid substitutions had occurred in PB2, HA, neuraminidase (NA), and NS2. The substituted amino acids in HA and NS2 of Taiwan2017 and PB2 of Guangdong2016 were predominant at the second and fourth passages, whereas those in HA and NA of Guangdong2016 were already predominant at the third passage. Glycine at position 129 (H3 numbering) of HA of Guangdong2016, which was near the receptor-binding pocket, was substituted by glutamic acid. The lysine residue at position 292 (N2 numbering) of NA of Guangdong2016, which influences sensitivity to NA inhibitors, was substituted by an arginine residue.

\section{Discussion}

The high pathogenicity of human H7N9 HPAIVs in chickens was similar to that of H7N9 HPAIVs isolated from chickens by another group, which belonged to the same phylogenetic tree cluster of the HA gene as Taiwan2017 and Guangdong2016. The pathogenicity of these H7N9 HPAIVs in chickens was apparently increased over that of Anhui2013, their ancestral LPAIV of human origin [16]. Meanwhile, the differences in pathogenicity and viral shedding between Taiwan2017 and Guangdong2016 might be attributable to amino acid substitutions relative to the consensus sequences 


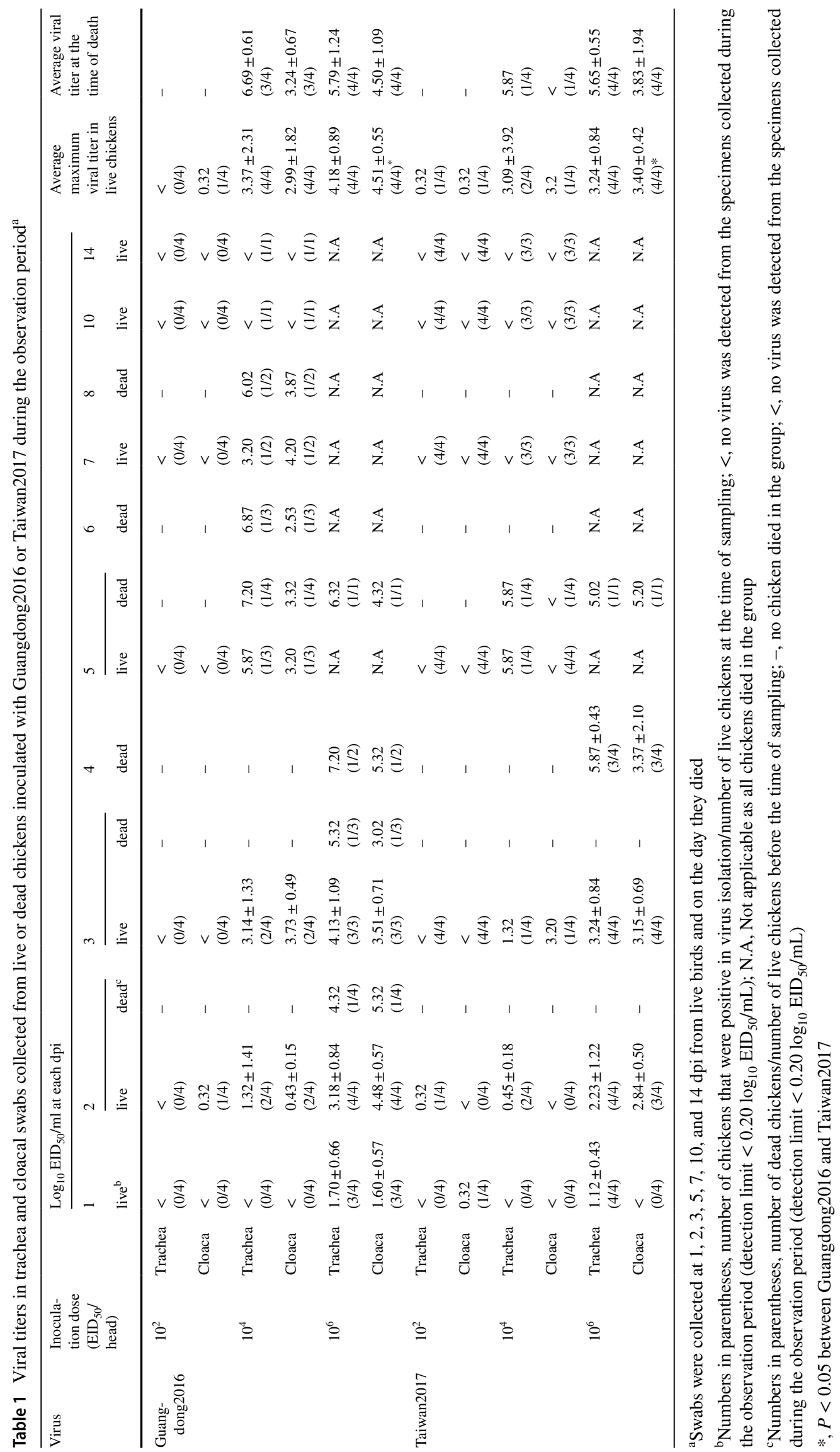




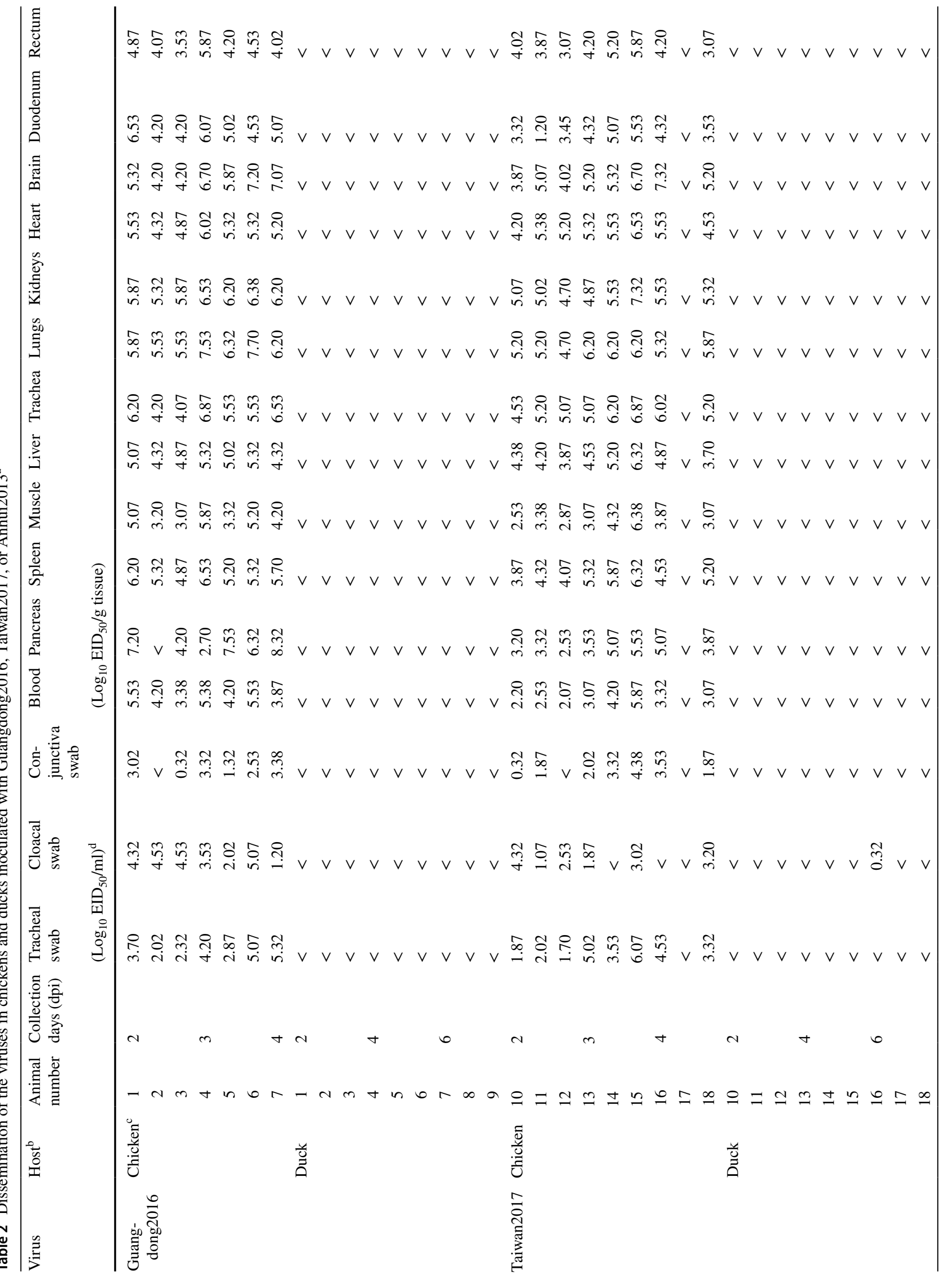




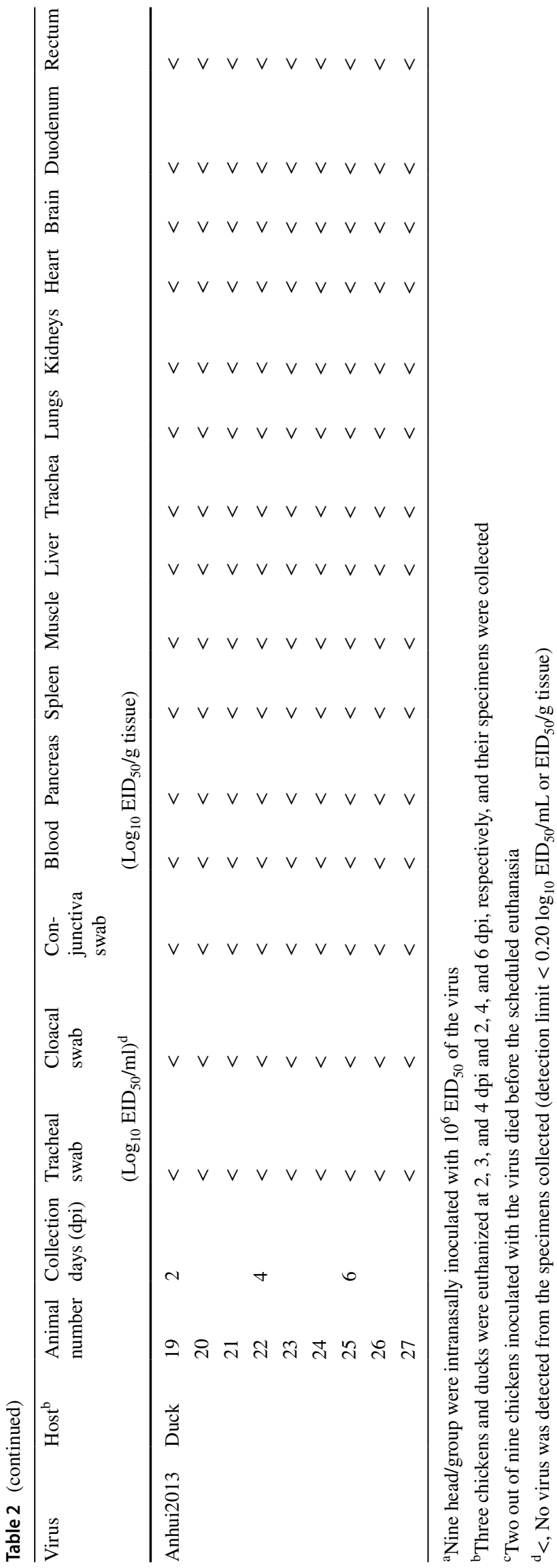

of avian H7N9 HPAIVs. Taiwan2017 exhibited a higher degree amino acid substitution, suggesting that Guangdong2016 retained more common features with chickenorigin H7N9 HPAIV. One amino acid substitution that arose in Guangdong2016 after egg passages was Lys292Arg in NA, which has been linked to reduced sensitivity to NA inhibition and less efficient replication in eggs for a human H3N2 isolate [24]. Reversion of this amino acid might increase the replication of Guangdong2016 in chickens. In addition, threonine at position 130 of HA1 in Taiwan 2017 generates an $\mathrm{N}$-glycosylation site at position 128 . The position is located near the receptor-binding site, and glycosylation at this site might affect the receptor preference of the virus, resulting in less efficient replication in chickens. In line with this hypothesis, deletion of $\mathrm{N}$-oligosaccharides at Asn123 or Asn149 in the HA protein of the H7 subtype has been reported to enhance hemadsorbing activity, suggesting that $\mathrm{N}$-glycosylation in the vicinity of the receptor-binding site can interfere with receptor-binding activity [25]. Meanwhile, it was reported that a 20 -amino acid extension of the C-terminus of the NS1 protein enhanced the replication and transmissibility of H9N2 strains in chickens [26]. However, only Taiwan 2017 was found to possess this extension. As the pathogenicity of HPAIVs is a multi-gene trait, further investigation is necessary to elucidate the contribution of these substitutions to the pathogenicity of H7N9 HPAIVs in chickens.

Chickens possess both $\alpha 2,6$ - and $\alpha 2,3$-linked sialic acids in their upper respiratory and intestinal tracts, whereas ducks mainly have $\alpha 2,3$-linked sialic acids, with $\alpha 2,6$-linked sialic acids being absent from their intestinal tracts [27]. These differences could partially explain the differences in the pathogenicity of the investigated viruses between chickens and ducks. The short length of the NA protein might also contribute to these differences. The H7N9 avian influenza viruses circulating in mainland China, including those used in this study, have a 5-amino-acid deletion in the stalk of the NA protein. An H7N1 LPAIV bearing a short-stalk NA was excreted in low titers from the cloaca of virus-infected Pekin ducks, whereas high titers of virus were shed from the oropharynx of virus-infected chickens compared to a recombinant virus that featured a 22-amino-acid insertion in the short-stalk NA [28]. It has also been reported that a 30-amino-acid deletion in an H11N9 virus hampered its replication in Pekin ducks but not in chickens [29]. The influence of the 5-amino-acid deletion in the NA protein of the H7N9 viruses on replication in ducks and chickens will need to be studied further. Meanwhile, there are some differences in immune-related genes between chickens and ducks, including RIG-I, which predominantly functions as an anti-influenza-virus sensor in ducks [30]. The absence of this gene in chickens has been suggested as a cause of their 
Table 3 Viral titers in trachea and cloacal swabs collected from ducks inoculated with $10^{6} \mathrm{EID}_{50}$ of Guangdong2016, Taiwan2017, or Anhui2013 during the observation period and antibody detection results ${ }^{\mathrm{a}}$

\begin{tabular}{|c|c|c|c|c|c|c|c|c|c|c|c|}
\hline \multirow[t]{2}{*}{ Virus } & \multirow[t]{2}{*}{$\begin{array}{l}\text { Animal } \\
\text { number }\end{array}$} & & \multicolumn{7}{|c|}{$\log _{10} \mathrm{EID}_{50} / \mathrm{ml}$ at each dpi ${ }^{\mathrm{b}}$} & \multicolumn{2}{|c|}{$\begin{array}{l}\text { Antibody } \\
\text { detection }^{\mathrm{c}}\end{array}$} \\
\hline & & & 1 & 2 & 3 & 5 & 7 & 10 & 14 & ELISA & HI \\
\hline \multirow[t]{8}{*}{ Guangdong2016 } & \multirow[t]{2}{*}{1} & Trachea & 0.87 & 3.45 & 4.02 & 3.32 & $<$ & $<$ & $<$ & + & $<$ \\
\hline & & Cloaca & $<$ & 0.32 & $<$ & $<$ & $<$ & $<$ & $<$ & & \\
\hline & \multirow[t]{2}{*}{2} & Trachea & $<$ & $<$ & $<$ & $<$ & $<$ & $<$ & $<$ & - & $<$ \\
\hline & & Cloaca & $<$ & 0.53 & $<$ & $<$ & $<$ & $<$ & $<$ & & \\
\hline & \multirow[t]{2}{*}{3} & Trachea & $<$ & $<$ & $<$ & $<$ & $<$ & $<$ & $<$ & + & $<$ \\
\hline & & Cloaca & $<$ & $<$ & $<$ & $<$ & $<$ & $<$ & $<$ & & \\
\hline & \multirow[t]{2}{*}{4} & Trachea & $<$ & $<$ & $<$ & $<$ & $<$ & $<$ & $<$ & + & $<$ \\
\hline & & Cloaca & $<$ & $<$ & $<$ & $<$ & $<$ & $<$ & $<$ & & \\
\hline \multirow[t]{8}{*}{ Taiwan2017 } & \multirow[t]{2}{*}{5} & Trachea & $<$ & $<$ & 3.02 & 0.53 & $<$ & $<$ & $<$ & + & $<$ \\
\hline & & Cloaca & $<$ & $<$ & 0.32 & $<$ & $<$ & $<$ & $<$ & & \\
\hline & \multirow[t]{2}{*}{6} & Trachea & $<$ & $<$ & $<$ & $<$ & $<$ & $<$ & $<$ & - & $<$ \\
\hline & & Cloaca & $<$ & $<$ & $<$ & $<$ & $<$ & $<$ & $<$ & & \\
\hline & \multirow[t]{2}{*}{7} & Trachea & $<$ & $<$ & $<$ & $<$ & $<$ & $<$ & $<$ & - & $<$ \\
\hline & & Cloaca & $<$ & $<$ & $<$ & $<$ & $<$ & $<$ & $<$ & & \\
\hline & \multirow[t]{2}{*}{8} & Trachea & $<$ & $<$ & $<$ & $<$ & $<$ & $<$ & $<$ & - & $<$ \\
\hline & & Cloaca & $<$ & $<$ & $<$ & $<$ & $<$ & $<$ & $<$ & & \\
\hline \multirow[t]{8}{*}{ Anhui2013 } & \multirow[t]{2}{*}{9} & Trachea & $<$ & $<$ & $<$ & $<$ & $<$ & $<$ & $<$ & - & $<$ \\
\hline & & Cloaca & $<$ & $<$ & $<$ & $<$ & 0.32 & $<$ & $<$ & & \\
\hline & \multirow[t]{2}{*}{10} & Trachea & $<$ & $<$ & $<$ & $<$ & $<$ & $<$ & $<$ & - & $<$ \\
\hline & & Cloaca & $<$ & $<$ & $<$ & $<$ & $<$ & $<$ & $<$ & & \\
\hline & \multirow[t]{2}{*}{11} & Trachea & $<$ & $<$ & $<$ & $<$ & $<$ & $<$ & $<$ & - & $<$ \\
\hline & & Cloaca & $<$ & $<$ & $<$ & $<$ & $<$ & $<$ & $<$ & & \\
\hline & \multirow[t]{2}{*}{12} & Trachea & $<$ & $<$ & $<$ & $<$ & $<$ & $<$ & $<$ & - & $<$ \\
\hline & & Cloaca & $<$ & $<$ & $<$ & $<$ & $<$ & $<$ & $<$ & & \\
\hline
\end{tabular}

${ }^{\text {a }}$ Specimens were collected at 1, 2, 3, 5, 7, 10, and 14 days postinoculation (dpi)

${ }^{\mathrm{b}}<$, No virus was detected from the specimens collected (detection limit $<0.20 \mathrm{EID}_{50} / \mathrm{mL}$ )

$\mathrm{c}_{-}$or + , The serum in surviving ducks at 14 dpi was negative or positive using the influenza A virus antibody test kit (IDEXX Laboratories, Inc.); < , No antibody was detected by HI test (detection limit $<4$ ) greater susceptibility to influenza virus infection compared to ducks [31].

In line with our findings in ducks, prior research using Pekin ducks and other H7N9 HPAIVs, namely A/chicken/ Heyuan/16876/2016, A/Chicken/Huizhou/HZ-3/2016, A/ Guangdong/Th005/2017, and A/Guangdong/Th008/2017, produced concordant findings [11]. These viruses, excluding A/Chicken/Huizhou/HZ-3/2016, were shed by Pekin ducks to some extent, whereas no shedding was observed for A/Chicken/Huizhou/HZ-3/2016. The low-pathogenic strain Anhui2013 rarely replicated in Cherry Valley ducks in our study, whereas another group reported that the virus replicated well and was shed at relatively high titers in oropharyngeal swabs from Pekin ducks [32]. Meanwhile, findings similar to ours have also been reported by another group who used Cherry Valley ducks as experimental models of infection [33]. The difference in sensitivity to influenza viruses between these two duck species might be related to differences in age at the time of experimentation, namely
4 weeks for Cherry Valley ducks and 2 weeks for Pekin ducks, as age-related effects have been reported previously for HPAIV infection [34].

To date, H7N9 HPAIVs have never been isolated from wild birds. However, these viruses may have the potential to acquire the ability to infect migratory birds via genetic mutation and genetic reassortment between viruses. Previously, an Asian H5 HPAIV caused an outbreak at a goose farm in Guangdong province in China in 1996 [35]. After a long period, the progeny viruses invaded North America and were rapidly disseminated in 2014-2015 [36, 37]. This rapid dissemination is reportedly associated with long-distance migratory birds [38]. In Japan, data revealed that the isolation rate of HPAIVs from dead wild birds rapidly increased to $9 \%$ in $2016-2017$, versus a rate of $0 \%-1 \%$ between the start of surveillance in 2008 and 2016 [39]. It has been reported that when mallard ducks were infected by HPAIVs isolated in North America in 2014, they shed more viruses in the oropharynx than ducks infected with 11 of the 12 other 
Table 4 Comparative alignment of deduced amino acid sequences among Guangdong2016, Taiwan2017, and HPAIVs of H7N9 subtype isolated from chickens ${ }^{\mathrm{a}}$

\begin{tabular}{|c|c|c|c|c|c|c|c|c|c|c|c|c|c|c|c|c|c|c|}
\hline & \multirow[t]{2}{*}{ Host } & \multicolumn{8}{|l|}{ PB2 } & \multicolumn{6}{|l|}{ PB1 } & \multicolumn{3}{|c|}{ PB1-F2 } \\
\hline & & 82 & 152 & 482 & 560 & 584 & 627 & 648 & 702 & 372 & 566 & 635 & & 542 & 646 & 41 & 42 & 57 \\
\hline Guangdong2016 & \multirow[t]{2}{*}{ Human } & $\mathbf{K}$ & A & $\mathrm{R}$ & I & I & $\mathrm{E}$ & $\mathrm{V}$ & $\mathrm{R}$ & M & $\mathrm{T}$ & $\mathrm{R}$ & $\mathrm{N}$ & v & M & $\mathrm{R}$ & $\mathrm{C}$ & $\mathrm{Y}$ \\
\hline Taiwan2017 & & $\mathrm{N}$ & $\mathrm{T}$ & $\mathrm{K}$ & $\mathrm{V}$ & $\mathrm{V}$ & $\mathrm{K}$ & I & K & $\mathrm{L}$ & M & K & $\mathrm{S}$ & & $\mathrm{L}$ & $\mathrm{H}$ & $\mathrm{Y}$ & $\mathrm{C}$ \\
\hline \multirow[t]{3}{*}{ Consensus sequence ${ }^{\mathrm{b}}$} & Chicken & $\mathrm{N} / \mathrm{V}$ & A & $\mathrm{K}$ & $\mathrm{V}$ & $\mathrm{V}$ & $\mathrm{E}$ & $\mathrm{V}$ & K & M & $\mathrm{T}$ & $\mathrm{K}$ & $\mathrm{N}$ & v & M & $\mathrm{H}$ & $\mathrm{Y}$ & $\mathrm{Y}$ \\
\hline & & \multicolumn{5}{|l|}{ PA } & PA-X & \multicolumn{8}{|l|}{$\mathrm{HA} 1^{\mathrm{c}}$} & \multirow{2}{*}{$\begin{array}{l}\text { HA2 }{ }^{\mathrm{c}} \\
42(42)\end{array}$} & \multicolumn{2}{|c|}{$\mathrm{NP}$} \\
\hline & & $66 \quad 228$ & 256 & 465 & 497 & $556 \quad 66$ & 228 & 137 (129) & )) 138 & $3(130)$ & 181 & $(172)$ & & $9(270$ & & & 89 & 399 \\
\hline Guangdong2016 & Human & $\mathrm{N}$ & $\mathrm{R}$ & $\mathrm{V}$ & $\mathrm{R}$ & G & $\mathrm{T}$ & $\mathbf{E}$ & I & & $\mathrm{K}$ & & $\mathrm{R}$ & & Q & & $\mathrm{P}$ & Q \\
\hline Taiwan2017 & & $S$ & $\mathrm{~K}$ & I & $\mathrm{K}$ & $\mathrm{H}$ & A & G & $\mathrm{T}$ & & $\mathrm{R}$ & & G & & $\mathbf{R}$ & & $\mathrm{H}$ & $\mathrm{H}$ \\
\hline \multirow[t]{3}{*}{ Consensus sequence } & Chicken & $\mathrm{N}$ & $\mathrm{R}$ & I & $\mathrm{K}$ & Q & $\mathrm{T}$ & $\mathrm{G}$ & I & & $\mathrm{R}$ & & G & & Q & & $\mathrm{P}$ & Q \\
\hline & & \multicolumn{8}{|l|}{$\mathrm{NA}^{\mathrm{d}}$} & \multicolumn{3}{|l|}{ M1 } & \multicolumn{4}{|c|}{ NS1 } & \multicolumn{2}{|c|}{ NS2 } \\
\hline & & $\begin{array}{l}49 \\
(48)\end{array}$ & $\begin{array}{l}72 \\
(75)\end{array}$ & $\begin{array}{l}166 \\
(169\end{array}$ & -170) & $\begin{array}{l}272 \\
(275)\end{array}$ & $\begin{array}{l}289 \\
(292)\end{array}$ & $\begin{array}{l}300 \\
(303)\end{array}$ & $\begin{array}{l}306 \\
(309)\end{array}$ & 165 & 205 & 236 & 80 & 180 & 216 & 218 & 60 & 115 \\
\hline Guangdong2016 & Human & $\mathrm{E}$ & M & $\mathrm{Y}$ & & I & $\mathbf{R}$ & I & $\mathbf{T}$ & I & I & $\mathrm{N}$ & S & I & $\mathrm{T}$ & - & $S$ & $\mathrm{~T}$ \\
\hline Taiwan2017 & & $\mathrm{G}$ & I & $\mathrm{H}$ & & $\mathrm{V}$ & $\mathrm{K}$ & $\mathrm{V}$ & $\mathrm{A}$ & M & I & $\mathrm{H}$ & $\mathrm{T}$ & V & $\mathrm{P}$ & $\mathrm{K}$ & $\mathrm{K}$ & $\mathbf{T}$ \\
\hline Consensus sequence & Chicken & $\mathrm{E}$ & M & $\mathrm{Y}$ & & I & $\mathrm{R} / \mathrm{K}$ & I & A & M & V & $\mathrm{N}$ & $S$ & I & $\mathrm{T}$ & - & $S$ & T/D/- \\
\hline
\end{tabular}

${ }^{\mathrm{a} B}$ Bold font denotes the substituted residue after egg passage, PB2: N82K; HA1: G137E; HA2: Q42R; NA: K289R and A306T; NS2: L115T

${ }^{\mathrm{b}}$ Amino acids consensus sequence in $24 \mathrm{HPAIV}$ s of H7N9 subtype isolated from chickens

${ }^{\mathrm{c}}$ Numbers in parentheses represent the positions in $\mathrm{H} 3$ numbering

${ }^{\mathrm{d}}$ Numbers in parentheses represent the positions in $\mathrm{N} 2$ numbering

strains of HPAIVs isolated before 2014 [40]. These results indirectly suggest that H5 HPAIVs have become adapted to migratory birds, enabling them to replicate well in wild birds over long periods. Thus, such adaptation of H7N9 HPAIVs to migratory birds could be possible in the future, facilitating their global dissemination. In this study, we demonstrated the preferential replication and the high pathogenicity of H7N9 HPAIVs isolated from humans in chickens. They did not replicate in and were not shed efficiently from domestic ducks, an observation that is important for epidemic control strategies for H7N9 HPAIVs.

Acknowledgements The authors are grateful to the National Institute for Viral Disease Control and Prevention, CCDC, for kindly providing the A/Guangdong/17SF003/2016. The authors would also like to thank Enago (http://www.enago.jp) for the English language review.

Funding This study was partially supported by the research project for improving food safety and animal health of the Ministry of Agriculture, Forestry and Fisheries of Japan.

\section{Compliance with ethical standards}

Conflict of interest The authors declare no conflicts of interest.

Ethical standard statement All experimental and animal procedures were approved by the ethics committee of the National Institute of Animal Health, Japan.

\section{References}

1. World Health Organization. Influenza at the human-animal interface. Monthly risk assessment summary as of 28 May 2018. https ://www.who.int/influenza/human_animal_interface/Influenza_ Summary_IRA_HA_interface_28_05_2018.pdf?ua=1. Accessed 16 Sept 2018.

2. EFSA (European Food Safety Authority), EFSA ECDC (European Centre for Disease Prevention and Control), EURL (European Reference Laboratory for Avian Influenza), Adlhoch C, Brouwer A, Kuiken T, Mulatti P, Smietanka K, Staubach C, Willeberg P, Barrucci F, Verdonck F (2018) Amato L and Baldinelli F (2018) Scientific report: avian influenza overview November 2017February 2018. EFSA J 16(3):5240. https://doi.org/10.2903/j. efsa.2018.5240

3. World Health Organization. Human infection with avian influenza A(H7N9) virus - update. Disease outbreak news of 17 February 2014. http://www.who.int/csr/don/2014_02_17/en/. Accessed 9 May 2018.

4. World Health Organization. Human infection with avian influenza A(H7N9) virus - Canada. Disease outbreak news of 1 February 2015. http://www.who.int/csr/don/01-february-2015-avian-influ enza/en/. Accessed 9 May 2018.

5. Chinese National Influenza Center. Chinese influenza weekly report. http://www.chinaivdc.cn/cnic/en/Surveillance/Weekl yReport/201807/t20180706_183192.htm. Accessed 16 Sept 2018

6. World Health Organization. Human infection with avian influenza A(H7N9) virus - China. Disease outbreak news of 22 February 2017. http://www.who.int/csr/don/22-february-2017-ah7n9-china /en/. Accessed 9 May 2018.

7. Wang D, Yang L, Zhu W, Zhang Y, Zou S, Bo H, Gao R, Dong J, Huang W, Guo J, Li Z, Zhao X, Li X, Xin L, Zhou J, Chen 
T, Dong L, Wei H, Li X, Liu L, Tang J, Lan Y, Yang J, Shu Y (2016) Two outbreak sources of influenza A (H7N9) viruses have been established in China. J Virol 90:5561-5573. https:// doi.org/10.1128/JVI.03173-15

8. Yang L, Zhu W, Li X, Chen M, Wu J, Yu P, Qi S, Huang Y, Shi W, Dong J, Zhao X, Huang W, Li Z, Zeng X, Bo H, Chen T, Chen W, Liu J, Zhang Y, Liang Z, Shi W, Shu Y, Wang D (2017) Genesis and spread of newly emerged highly pathogenic H7N9 avian viruses in mainland China. J Virol 91:e01277-17. https:// doi.org/10.1128/jvi.01277-17

9. World Organisation for Animal Health. Update on highly pathogenic avian influenza in animals (Type $\mathrm{H} 5$ and H7). http://www. oie.int/en/animal-health-in-the-world/update-on-avian-influenza/. Accessed 16 Sept 2018

10. Chen J, Zhang J, Zhu W, Zhang Y, Tan H, Liu M, Cai M, Shen J, Ly H, Chen J (2017) First genome report and analysis of chicken H7N9 influenza viruses with poly-basic amino acids insertion in the hemagglutinin cleavage site. Sci Rep 7:9972. https://doi. org/10.1038/s41598-017-10605-6

11. Qi W, Jia W, Liu D, Li J, Bi Y, Xie S, Li B, Hu T, Du Y, Xing L, Zhang J, Zhang F, Wei X, Eden JS, Li H, Tian H, Li W, Su G, Lao G, Xu C, Xu B, Liu W, Zhang G, Ren T, Holmes EC, Cui J, Shi W, Gao GF, Liao M (2018) Emergence and adaptation of a novel highly pathogenic H7N9 Influenza virus in birds and humans from a 2013 human-infecting low-pathogenic ancestor. J Virol 92:e00921-17. https://doi.org/10.1128/jvi.00921-17

12. Quan C, Shi W, Yang Y, Yang Y, Liu X, Xu W, Li H, Li J, Wang Q, Tong Z, Wong G, Zhang C, Ma S, Ma Z, Fu G, Zhang Z, Huang Y, Song H, Yang L, Liu WJ, Liu Y, Liu W, Gao GF, Bi Y (2018) New threats of H7N9 influenza virus: the spread and evolution of highly and low pathogenic variants with high genomic diversity in Wave Five. J Virol. https://doi.org/10.1128/jvi.00301 $-18$

13. Belser JA, Gustin KM, Pearce MB, Maines TR, Zeng H, Pappas C, Sun X, Carney PJ, Villanueva JM, Stevens J, Katz JM, Tumpey TM (2013) Pathogenesis and transmission of avian influenza A (H7N9) virus in ferrets and mice. Nature 501:556-559. https:// doi.org/10.1038/nature12391

14. Watanabe T, Kiso M, Fukuyama S, Nakajima N, Imai M, Yamada S, Murakami S, Yamayoshi S, Iwatsuki-Horimoto K, Sakoda Y, Takashita E, McBride R, Noda T, Hatta M, Imai H, Zhao D, Kishida N, Shirakura M, de Vries RP, Shichinohe S, Okamatsu M, Tamura T, Tomita Y, Fujimoto N, Goto K, Katsura H, Kawakami E, Ishikawa I, Watanabe S, Ito M, Sakai-Tagawa Y, Sugita Y, Uraki R, Yamaji R, Eisfeld AJ, Zhong G, Fan S, Ping J, Maher EA, Hanson A, Uchida Y, Saito T, Ozawa M, Neumann G, Kida H, Odagiri T, Paulson JC, Hasegawa H, Tashiro M, Kawaoka Y (2013) Characterization of H7N9 influenza A viruses isolated from humans. Nature 501:551-555. https://doi.org/10.1038/natur e12392

15. Kalthoff D, Bogs J, Grund C, Tauscher K, Teifke JP, Starick E, Harder T, Beer M (2014) Avian influenza H7N9/13 and H7N7/13: a comparative virulence study in chickens, pigeons, and ferrets. $\mathrm{J}$ Virol 88:9153-9165. https://doi.org/10.1128/jvi.01241-14

16. Uchida Y, Kanehira K, Takemae N, Hikono H, Saito T (2017) Susceptibility of chickens, quail, and pigeons to an H7N9 human influenza virus and subsequent egg-passaged strains. Arch Virol 162:103-116. https://doi.org/10.1007/s00705-016-3090-6

17. Shi J, Deng G, Kong H, Gu C, Ma S, Yin X, Zeng X, Cui P, Chen Y, Yang H, Wan X, Wang X, Liu L, Chen P, Jiang Y, Liu J, Guan Y, Suzuki Y, Li M, Qu Z, Guan L, Zang J, Gu W, Han S, Song Y, Hu Y, Wang Z, Gu L, Yang W, Liang L, Bao H, Tian G, Li Y, Qiao C, Jiang L, Li C, Bu Z, Chen H (2017) H7N9 virulent mutants detected in chickens in China pose an increased threat to humans. Cell Res 27:1409-1421. https://doi.org/10.1038/cr.2017
18. Food and Agriculture Organization of the United Nations. H7N9 situation update. http://www.fao.org/ag/againfo/programmes/en/ empres/H7N9/Situation_update.html. Accessed 16 Sept 2018

19. Gao R, Cao B, Hu Y, Feng Z, Wang D, Hu W, Chen J, Jie Z, Qiu H, Xu K, Xu X, Lu H, Zhu W, Gao Z, Xiang N, Shen Y, He Z, Gu Y, Zhang Z, Yang Y, Zhao X, Zhou L, Li X, Zou S, Zhang Y, Li X, Yang L, Guo J, Dong J, Li Q, Dong L, Zhu Y, Bai T, Wang S, Hao P, Yang W, Zhang Y, Han J, Yu H, Li D, Gao GF, Wu G, Wang Y, Yuan Z, Shu Y (2013) Human infection with a novel avian-origin influenza A (H7N9) virus. N Engl J Med 368:1888-1897. https:// doi.org/10.1056/NEJMoa1304459

20. Zhang F, Bi Y, Wang J, Wong G, Shi W, Hu F, Yang Y, Yang L, Deng X, Jiang S, He X, Liu Y, Yin C, Zhong N, Gao GF (2017) Human infections with recently-emerging highly pathogenic H7N9 avian influenza virus in China. J Infect 75:71-75. https:// doi.org/10.1016/j.jinf.2017.04.001

21. Yang JR, Liu MT (2017) Human infection caused by an avian influenza A (H7N9) virus with a polybasic cleavage site in Taiwan, 2017. JFMA 116:210-212. https://doi.org/10.1016/j. jfma.2017.02.011

22. Reed LJ, Muench H (1938) A simple method of estimating fifty per cent endpoints. Am J Epidemiol 27:493-497

23. Organization WHO (2002) WHO manual on animal influenza diagnosis and surveillance. WHO/CDS/CSR/ NCS/2002.5.

24. Yen H-L, Herlocher LM, Hoffmann E, Matrosovich MN, Monto AS, Webster RG, Govorkova EA (2005) Neuraminidase inhibitorresistant influenza viruses may differ substantially in fitness and transmissibility. Antimicrob Agents Chemother 49:4075-4084

25. Ohuchi M, Ohuchi R, Feldmann A, Klenk HD (1997) Regulation of receptor binding affinity of influenza virus hemagglutinin by its carbohydrate moiety. J Virol 71:8377-8384

26. Kong W, Liu L, Wang Y, He Q, Wu S, Qin Z, Wang J, Sun H, Sun Y, Zhang R (2015) C-terminal elongation of NS1 of H9N2 influenza virus induces a high level of inflammatory cytokines and increases transmission. J Gen Virol 96:259-268

27. Costa T, Chaves AJ, Valle R, Darji A, van Riel D, Kuiken T, Majó N, Ramis A (2012) Distribution patterns of influenza virus receptors and viral attachment patterns in the respiratory and intestinal tracts of seven avian species. Vet Res 43:28

28. Hoffmann T, Munier S, Larcher T, Soubieux D, Ledevin M, Esnault E, Tourdes A, Croville G, Guérin J-L, Quéré P (2012) Length variations in the NA stalk of an H7N1 influenza virus have opposite effects on viral excretion in chickens and ducks. J Virol 86:584-588

29. Li J, Cardona CJ (2010) Adaptation and transmission of a wild duck avian influenza isolate in chickens. Avian Dis 54:586-590

30. Magor KE, Navarro DM, Barber MR, Petkau K, Fleming-Canepa X, Blyth GA, Blaine AH (2013) Defense genes missing from the flight division. Dev Comp Immunol 41:377-388

31. Barber MR, Aldridge JR, Webster RG, Magor KE (2010) Association of RIG-I with innate immunity of ducks to influenza. Proc Natl Acad Sci 107:5913-5918

32. Pantin-Jackwood MJ, Miller PJ, Spackman E, Swayne DE, Susta L, Costa-Hurtado M, Suarez DL (2014) Role of poultry in the spread of novel H7N9 influenza virus in China. J Virol 88:53815390. https://doi.org/10.1128/jvi.03689-13

33. Hiono T, Okamatsu M, Yamamoto N, Ogasawara K, Endo M, Kuribayashi S, Shichinohe S, Motohashi Y, Chu D-H, Suzuki M (2016) Experimental infection of highly and low pathogenic avian influenza viruses to chickens, ducks, tree sparrows, jungle crows, and black rats for the evaluation of their roles in virus transmission. Vet Microbiol 182:108-115

34. Löndt BZ, Núñez A, Banks J, Alexander DJ, Russell C, RichardLöndt AC, Brown IH (2010) The effect of age on the pathogenesis of a highly pathogenic avian influenza (HPAI) H5N1 virus 
in Pekin ducks (Anas platyrhynchos) infected experimentally. Influenza Other Respir Viruses 4:17-25

35. Xu X, Subbarao K, Cox NJ, Guo Y (1999) Genetic characterization of the pathogenic influenza A/Goose/Guangdong/1/96 (H5N1) virus: similarity of its hemagglutinin gene to those of H5N1 viruses from the 1997 outbreaks in Hong Kong. Virology 261:15-19

36. Ip HS, Torchetti MK, Crespo R, Kohrs P, DeBruyn P, Mansfield KG, Baszler T, Badcoe L, Bodenstein B, Shearn-Bochsler V (2015) Novel Eurasian highly pathogenic avian influenza A H5 viruses in wild birds, Washington, USA, 2014. Emerg Infect Dis $21: 886$

37. U.S. Department of Agriculture, Animal and Plant Health Inspection Service. HPAI 2014/15 confirmed detections. https://www. aphis.usda.gov/aphis/ourfocus/animalhealth/animal-disease-infor mation/avian-influenza-disease/sa_detections_by_states/hpai2014-2015-confirmed-detections. Accessed 10 May 2018.

38. Lycett SJ, Bodewes R, Pohlmann A, Banks J, Bányai K, Boni MF, Bouwstra R, Breed AC, Brown IH, Chen H, Dan A (2016) Role for migratory wild birds in the global spread of avian influenza H5N8. Science (New York, NY) 354:213-217. https://doi. org/10.1126/science.aaf8852

39. Ministry of Environment, Government of Japan. Information on highly pathogenic influenza. https://www.env.go.jp/nature/dobut su/bird_flu/index.html. Accessed 16 Sept 2018.

40. Pantin-Jackwood MJ, Costa-Hurtado M, Shepherd E, DeJesus E, Smith D, Spackman E, Kapczynski DR, Suarez DL, Stallknecht DE, Swayne DE (2016) Pathogenicity and transmission of H5 and $\mathrm{H} 7$ highly pathogenic avian influenza viruses in mallards. J Virol 90:9967-9982 